NBER WORKING PAPER SERIES

EFFICIENT PROGRAMS TO SUPPORT BUSINESSES DURING AND AFTER LOCKDOWNS

Thomas Philippon

Working Paper 28211

http://www.nber.org/papers/w28211

\author{
NATIONAL BUREAU OF ECONOMIC RESEARCH \\ 1050 Massachusetts Avenue \\ Cambridge, MA 02138 \\ December 2020
}

This paper is based on the keynote RCFS address during the 2020 SFS Cavalcade. I am grateful to Olivier Blanchard, Jean Pisani Ferry, Andrew Ellul, Isil Erel, and Uday Rajan for their comments. Send correspondence to Thomas Philippon, tphilipp@stern.nyu.edu. The views expressed herein are those of the author and do not necessarily reflect the views of the National Bureau of Economic Research.

NBER working papers are circulated for discussion and comment purposes. They have not been peer-reviewed or been subject to the review by the NBER Board of Directors that accompanies official NBER publications.

(C) 2020 by Thomas Philippon. All rights reserved. Short sections of text, not to exceed two paragraphs, may be quoted without explicit permission provided that full credit, including () notice, is given to the source. 
Efficient Programs to Support Businesses During and After Lockdowns

Thomas Philippon

NBER Working Paper No. 28211

December 2020

JEL No. D24,G33,G38,H12

\section{$\underline{\text { ABSTRACT }}$}

I analyze efficient government interventions to mitigate financial distress during a severe macroeconomic downturn. At the macroeconomic level, the key variable is the gap between the real wage and the shadow cost of labor. This gap is large when unemployment is high. At the micro level, laissez-faire leads to excessive liquidation of businesses but an indiscriminate bailout prevents efficient reallocations and implies a large transfer from taxpayers to existing private creditors. I show that a cost-efficient intervention can be achieved with a continuation premium, whereby the government agrees to reduce its claims by the same haircut as private creditors plus a fixed premium.

Thomas Philippon

New York University

Stern School of Business

44 West 4th Street, Suite 9-190

New York, NY 10012-1126

and NBER

tphilipp@stern.nyu.edu 


\title{
Efficient Programs to Support Businesses During and After Lockdowns*
}

\author{
Thomas Philippon, New York University, CEPR, and NBER
}

December 2020

\begin{abstract}
I analyze efficient government interventions to mitigate financial distress during a severe macroeconomic downturn. At the macroeconomic level, the key variable is the gap between the real wage and the shadow cost of labor. This gap is large when unemployment is high. At the micro level, laissez-faire leads to excessive liquidation of businesses but an indiscriminate bailout prevents efficient reallocations and implies a large transfer from taxpayers to existing private creditors. I show that a cost-efficient intervention can be achieved with a continuation premium, whereby the government agrees to reduce its claims by the same haircut as private creditors plus a fixed premium. (D24, G33, G38, H12)
\end{abstract}

Governments responded to the COVID-19 crisis with a lockdown of nonessential industries, together with measures to protect firms and households. European countries used a combination of tax deferrals, guaranteed loans, and equity injections. The United States relied on extended unemployment insurance and a program of bank loans to small and medium-size enterprises (SMEs), which can be partially or totally turned into government-financed grants as a function of the proportion of workers kept by the firm. The scale of the interventions is large. For instance, the German stabilization fund totals $€ 600$ billion ( $€ 400$ billion for liquidity guarantees, $€ 100$ billion for subsidized loans, and $€ 100$ billion for equity injections). By the end of May 2020, the French government had granted loan guarantees to more than 400,000 businesses.

As firms accumulate debt, the risk of a large wave of insolvencies increases. The question then becomes: will there be excessive liquidation? When the bankruptcy system is efficient, creditors and firms reach a privately optimal allocation. In times of high unemployment, however, I argue that business failures are likely to be inefficiently high and I characterized optimal mitigation policies.

The reason for excess liquidation is involuntary unemployment at the prevailing wage. The wage is the cost of labor perceived by the firms. When wages are rigid, a gap appears between the cost of labor and the

*This paper is based on the keynote RCFS address during the 2020 SFS Cavalcade. I am grateful to Olivier Blanchard, Jean Pisani Ferry, Andrew Ellul, Isil Erel, and Uday Rajan for their comments. Send correspondence to Thomas Philippon, tphilipp@stern.nyu.edu . 
shadow value of unemployment. This gap creates inefficient liquidations from a macroeconomic perspective even when there are no bankruptcy costs and even when debt restructuring is privately efficient.

The key result of the paper is that it is optimal for the government to offer a continuation premium in order to induce efficient restructuring, liquidation and continuation. I show that laissez-faire liquidations are socially excessive when unemployment is high. On the other hand it is not efficient to prevent all liquidations as some businesses are not viable and should be closed. The optimal policy is then to nudge private incentives towards continuation by offering a continuation premium to the firm and its claim-holders. The difficult issue is to calibrate and target the continuation premium to the right set of firms. I characterize full information interventions as well as wage subsidy schemes. Wage subsidy schemes can achieve efficiency but are typically quite costly for tax-payers.

The most important result of the paper relates to optimal interventions when the government has limited information about the quality of each firm. This issue is particularly relevant in the case of the COVID19 crisis since the number of loans guaranteed by governments is orders of magnitude larger than in any previous recessions. I show that the government can use the behavior of private creditors to reach the efficient outcome even when it does not observe firm quality, and thus cannot by itself decide which firm should be saved and which one should be liquidated. Theorem 2 shows that the efficient outcome is achieved by indexing the haircut on government loans on the haircut of private creditors plus a continuation premium. A key feature is that the premium is conditional on the existence of a private workout.

The paper relates to the literature on the mitigation of financial distress. Several recent contributions were motivated by the 2009 crisis. For example, Philippon and Skreta (2012) study optimal mitigation policies against adverse selection when credit markets freeze, and Philippon and Schnabl (2013) study optimal interventions in a banking system subject to debt overhang. These papers also contain discussion of the earlier literature. Glode and Opp (2020) study renegotiations when agents are both debtors and creditors, and their willingness to renegotiate their claims depends on how they expect their own debts to be renegotiated by others.

This paper also relates to recent work on the macroeconomic impact of COVID-19. On the macroeconomic side, Eichenbaum et al. (2020), Alvarez et al. (2020), and Jones et al. (2020) build DSGE models with contagion risk to study the joint dynamics of employment and infections. Guerrieri et al. (2020) study how a supply shock in one sector (e.g., a lockdown) can create demand shortages in other, unaffected sectors.

On the policy side, Hanson et al. (2020) study how the Federal Reserve and the Treasury responded to the pandemic. Blanchard et al. (2020) discuss the rationale for subsidies to wages and debt restructuring. Brunnermeier and Krishnamurthy (2020) argue that the Federal Reserve should act to directly support the bond market, and, with the help of the Treasury, to subsidize loans to SMEs.

On the empirical side, several papers attempt to estimate the impact of COVID-19 on firms' cash flows. Gourinchas et al. (2020) estimate the impact of the COVID-19 crisis on business failures among SMEs in 17 countries. Absent government support, they predict a 9 percentage points increase in the failure rate of SMEs. The impact is most severe in Accommodation \& Food Services, Arts, Entertainment \& Recreation, Education, and Other Services. The fiscal cost of an intervention that narrowly targets at risk firms is around $0.5 \%$ of gross national product (GDP), while non-targeted subsidies can be substantially 
more expensive (1.82\% of GDP). Carletti et al. (2020) study the drop in profits and the equity shortfall in Italy during the COVID-19 lockdown. They estimate that a 3-month lockdown generates a drop in profits of about $10 \%$ of GDP, and that $17 \%$ of the firms become financially distressed. Also, in the context of COVID-19, Schivardi et al. (2020) argue that the existing literature has overestimated the risks of propping up zombie firms.

The contribution of this paper is to propose an explicit model of excessive liquidation and to derive the optimal policy response when the government has limited information.

\section{Baseline Model}

\subsection{Technology and preferences}

I consider a one period model. The economy has a unit mass of firms and a unit mass of households. The representative household has quasi-linear preferences over consumption $C$ and labor $N$ :

$$
U=C-\gamma(N)
$$

where $\gamma$ is increasing, strictly convex and such that $\gamma^{\prime}(0)=0$.

Firm $i \in[0,1]$ can produce output $y_{i}$ using labor $n_{i}$ according to the function

$$
y_{i}=z_{i} \min \left(n_{i}, 1\right)
$$

where productivity $z_{i}$ is the only parameter that varies across firms, so from now on we index each firm by its $z$. The cumulative distribution (pre-COVID-19) is $F_{0}(z)$ defined over $(0, \infty)$ with limits such that $F_{0}(0)=0$ and $F_{0}(\infty)=1$. Instead of hiring labor for production, a firm can be liquidated to yield $\lambda<1$ units of output. Thus, some firms will be active and some firms will be liquidated. Let $\Lambda$ be the set of liquidated firms. Firms hire labor at the beginning of the period and labor market clearing requires

$$
N=\int_{z \notin \Lambda} n(z) f_{0}(z) d z
$$

and aggregate welfare is

$$
U\{\Lambda ; n(.)\}=\int_{z \notin \Lambda} z n(z) f_{0}(z) d z+\lambda \int_{z \in \Lambda} f_{0}(z) d z-\gamma(N) .
$$

\subsection{Pre-COVID-19 planner allocation and competitive equilibrium}

\subsubsection{Planner's problem}

It is clear that $n=1$ for all active firms. To see why, consider two firms with the same $z$ and suppose that $n=0.5$ : this would produce $z$, but it would be dominated by $n=1$ for one firm and liquidation for the other, which would produce $z+\lambda$. The planner thus only needs to choose a cutoff $z^{*}$ above which firms are active at maximum employment and below which they are liquidated: $\Lambda=\left[0, z^{*}\right]$ for some $z^{*}$. The labor 


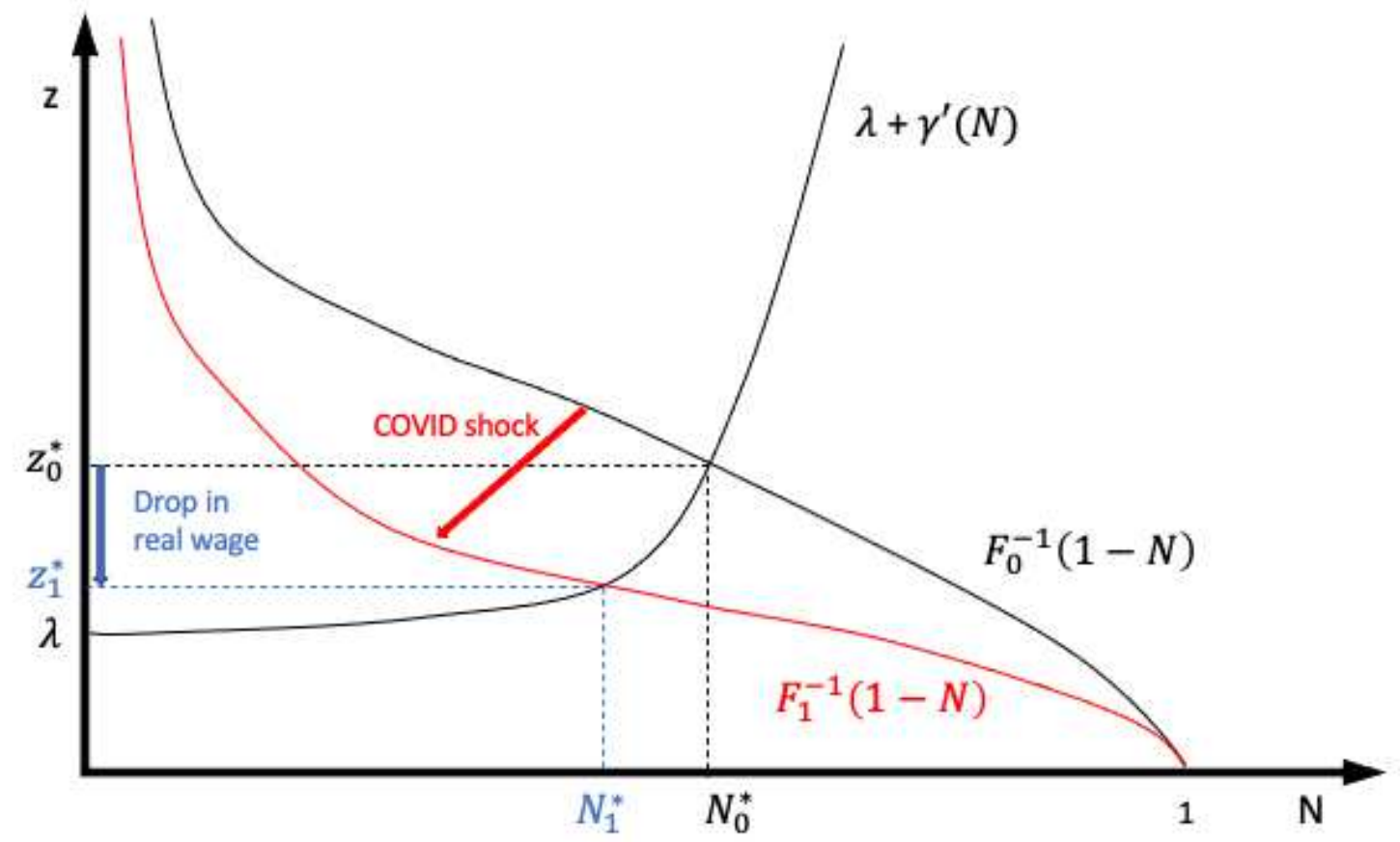

market clearing condition is then simply

$$
N=\int_{z^{*}}^{1} f_{0}(z) d z=1-F_{0}\left(z^{*}\right)
$$

The planner solves

$$
\max \int_{z^{*}}^{1} z f_{0}(z) d z-\gamma(N)+\lambda \int_{0}^{z^{*}} f_{0}(z) d z
$$

The first-order condition is

$$
z^{*}=\lambda+\gamma^{\prime}(N)
$$

At the social optimum, the productivity of the marginal firm must equal the opportunity cost of nonliquidation plus the shadow cost of labor. Since $\gamma^{\prime}(0)=0$ and $\lambda<1$, we have the following result.

Lemma 1. There exists a unique optimal cutoff that solves $z_{0}^{*}=\lambda+\gamma^{\prime}\left(1-F_{0}\left(z_{0}^{*}\right)\right)$.

Figure 1 depicts the equilibrium.

\subsubsection{Competitive equilibrium}

To solve the competitive equilibrium, we need to find the equilibrium (real) wage $w$. The profits of an active firm are

$$
\pi=z-w .
$$


The marginal firm in the competitive equilibrium is indifferent between production and liquidation

$$
\pi\left(z^{c}\right)=\lambda
$$

which implies

$$
z^{c}=w+\lambda .
$$

From the household's optimal labor supply, we have

$$
w=\gamma^{\prime}(N)
$$

Therefore, $z^{c}=\lambda+\gamma^{\prime}(N)$, which is the same condition as in the planner's problem, and, therefore, $z^{c}=z^{*}$.

Lemma 2. The competitive equilibrium is efficient.

\subsection{COVID-19 shock with flexible wages}

I model the COVID-19 shock as a negative change in the distribution of productivity. This captures the idea that some businesses are unaffected by lockdowns - or even benefit from it as in the case of Amazon or Zoom - while some businesses are severely affected. Formally, let $F_{0}($.$) denote the pre-COVID-19$ distribution of project quality, and let $F_{1}($.$) be the post-COVID-19 distribution. F_{0}($.$) dominates F_{1}($.$) in$ the first-order stochastic dominance sense: $F_{0}(z) \leq F_{1}(z)$ for all $z$. Let $z_{0}^{*}$ and $N_{0}^{*}$ be the pre-COVID-19 liquidation cutoff and employment.

Lemma 3. The efficient allocation in the post-COVID-19 economy is characterized by $z_{1}^{*}=\lambda+\gamma^{\prime}\left(1-F\left(z_{1}^{*}\right)\right)$. Wages and employment are lower than in the pre-COVID-19 equilibrium: $w_{1}^{*}<w_{0}^{*}$, and $N_{1}^{*}<N_{0}^{*}$. The liquidation cutoff is lower $z_{1}^{*}<z_{0}^{*}$, but the liquidation rate is higher: $F_{1}\left(z_{1}^{*}\right)>F_{0}\left(z_{0}^{*}\right)$.

Proof. Consider the labor market equilibrium conditions in the $(N, z)$ space. Demand $N=1-F(z)$ describes a downward slopping curve. Supply $\gamma^{\prime}(N)=z-\lambda$ describes an upward slopping curve. The results follows from $F_{0}()<.F_{1}($.$) . This leads to z_{1}^{*}<z_{0}^{*}$ and $w_{1}^{*}<w_{0}^{*}$ since $w^{*}=z^{*}-\lambda$. The fact that $F_{1}\left(z^{*}\right)>F_{0}\left(z_{0}^{*}\right)$ follows from the fact that $\gamma^{\prime}(N)=z-\lambda$ is upward sloping.

COVID-19 lowers firm quality, output, and employment, as shown in Figure 1. In an efficient labor market this decreases the real wage, which helps limit the negative impact of the COVID-19 shock on firms'

profits. The productivity of the marginal firm is now $z_{1}^{*}=\lambda+w_{1}^{*}$, which is less than $z_{0}^{*}$. In equilibrium there are fewer firms, lower wages, and lower employment. In the following sections, I study excess liquidation, which is defined as liquidation above and beyond the efficient level thus defined.

\subsection{COVID-19 shock with downward rigid wages}

Suppose that wages are downward rigid, so $w=w_{0}$ after the COVID-19 shock. Let $\hat{z}_{1}$ be the liquidation cutoff. The marginal firm is such that $\hat{z}_{1}=\lambda+w$. With rigid wages we have $\hat{z}_{1}=\lambda+w_{0}=z_{0}^{*}$. 


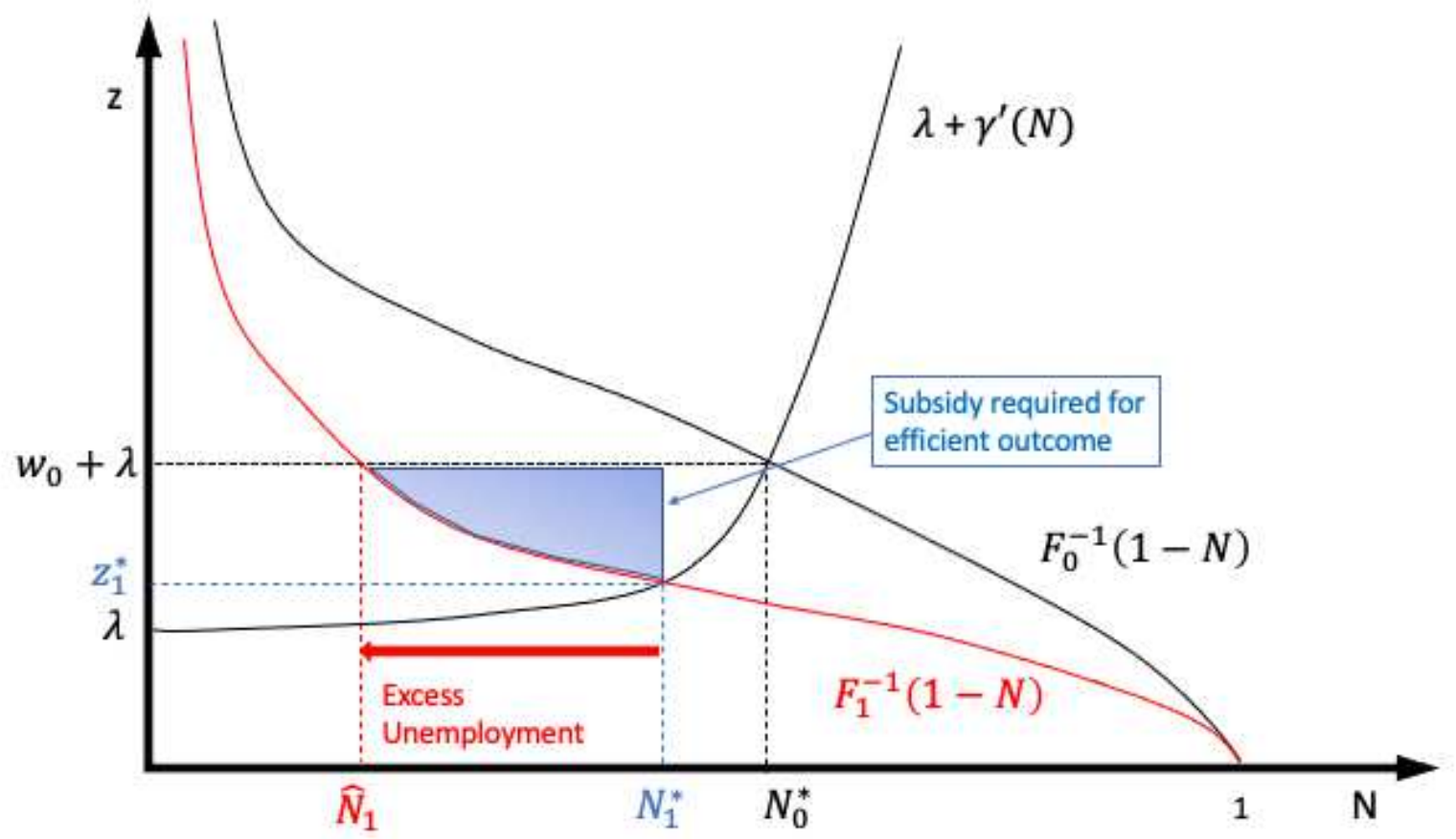

Proposition 1. With downward rigid wages we have excess liquidation, $\hat{z}_{1}=z_{0}^{*}>z_{1}^{*}$, and excess unemployment $F_{1}\left(\lambda+w_{0}\right)-F_{1}\left(z_{1}^{*}\right)$.

In the efficient economy, the COVID-19 recession lowers the real wage, which mitigates the downturn. When wages are rigid, $\hat{z}_{1}$ cannot adjust and remains at $z_{0}^{*}$. This increases liquidation above and beyond the efficient level. Figure 2 depicts the equilibrium.

The figure captures the features of a Keynesian recession. As shown by Guerrieri et al. (2020), a supply shock in one sector that creates demand deficiency in an another can generate a recession. The reason for excess liquidation is involuntary unemployment at the prevailing wage. The wage is the cost of labor perceived by the firms. The shadow value of labor, however, is $\gamma^{\prime}(\hat{N})$. When wages are downward rigid, we have $w_{0}>\gamma^{\prime}(\hat{N})$.

\section{Analysis of Government Interventions}

We have seen that laissez-faire leads to excessive liquidation and unemployment when wages are rigid. This gap creates some scope for policy interventions. Let us now describe various interventions, starting with a full-information benchmark. 


\subsection{Efficient Continuation Subsidy under Full Information}

Suppose for now that the government can observe the quality $z$ of each firm. To implement the efficient allocation the government needs to offer a continuation subsidy to all firm between $z_{1}^{*}$ and $\hat{z}_{1}$ so as to make continuation privately optimal. Let $m$ be the subsidy granted to firms conditional on continuation.

Proposition 2. The conditional continuation subsidy $m(z)=w_{0}+\lambda-z$ for all $z \in\left[z_{1}^{*}, \lambda+w_{0}\right]$ and $m=0$ otherwise implements the efficient allocation $\left(z_{1}^{*}, N_{1}^{*}\right)$ at a cost $T^{c s}=\int_{z_{1}^{*}}^{w_{0}+\lambda} m(z) f_{1}(z) d z$. This subsidy is the cost-minimizing intervention among all interventions that respect the principle that no creditor should be worse off than in liquidation.

The idea is simple, as shown in Figure 2. Notice first that since $m=0$ for $z \notin\left(z^{*}, \hat{z}\right)$, the mitigation policy does not affect strong firms. For firms with $z<z^{*}$ the subsidy is zero therefore they are liquidated. We can thus focus on firms where $z \in\left[z_{1}^{*}, \hat{z}_{1}\right]$. Liquidation yields $\lambda$. Continuation yields $z-w+m$. All firms in $\left[z_{1}^{*}, \hat{z}_{1}\right]$ therefore (weakly) prefer to continue. The full information mitigation has the following properties:

- it implements the efficient allocation;

- only socially viable firms are subsidized;

- it is the least costly intervention among the ones that only employ subsidies.

The full information case is not realistic, however, since governments cannot observe $z$ directly. One possible implementation is via a profit compensation scheme. For a given wage, firm profits $\pi=z-w$ reveal the level of productivity, so the subsidy also could be written as $m(z)=\lambda-\pi$ for all $\pi \in\left[\lambda+w_{1}^{*}-w_{0}, \lambda\right]$.

In practice, however, profits are not observable in real time, and they can be manipulated. Therefore, the assumption that the government can recover $z$ from $\pi$ is not realistic. In the following sections, we study limited information interventions.

\subsection{Uniform wage subsidy}

The optimal allocation above requires a lot of granular information that the government is unlikely to have. In particular, it requires the government to estimate the liquidation value as well as the going-concern value of each firm.

A wage subsidy can restore efficiency even when the government does not observe $z$. Suppose that the state pays a fraction $s$ of the wage bill. The marginal firm is then defined by $\hat{z}=\lambda+\left(1-s^{w}\right) w_{0}$, and the subsidy can be adjusted to achieve $\hat{z}_{1}=z_{1}^{*}=w_{1}^{*}+\lambda$ by choosing $s^{w}=\frac{w_{0}-w_{1}^{*}}{w_{0}}$. In that case, the profits of an active firm are $\pi=z-\left(1-s^{w}\right) w=z-w_{1}^{*}$, which is exactly what they would be under the efficient equilibrium.

Proposition 3. A wage subsidy $s^{w}=\frac{w_{0}-w_{1}^{*}}{w_{0}}$ financed by lump-sum taxes restores efficiency, $\hat{z}_{1}=z_{1}^{*}$, but at a cost $T^{w s}>T^{c s}$. 
The issue with such a subsidy is that it does not keep firms at their indifference point. The only firm that stays at its outside option is the marginal one $z_{1}^{*}$. For this firm, $\pi\left(z_{1}^{*}\right)=\lambda$. For all other active firms, however, $\pi>\lambda$. The firms that would have closed receive more than is required to keep them open, and the ones would have continued even under rigid wages get a rent. This is why the program is costly. The fiscal cost is in fact proportional to the aggregate post-COVID-19 wage bill, which is typically very large: $T^{w s}=s^{w} w_{0}\left(1-F\left(z_{1}^{*}\right)\right)$.

To limit the costs of wage subsidy programs, they can be made available only to those sectors of the economy, such as hotels and restaurants, where we have reason to expect the COVID-19 shock to be particularly large.

\subsection{Liquidation tax}

The final way to implement efficient allocation is to tax liquidations. Suppose that, in case of liquidation, the government taxes the liquidation proceeds at rate $\tau$. The marginal firm is then defined by $\hat{z}=(1-\tau) \lambda+w_{0}$. As before, we aim for $\hat{z}=z_{1}^{*}$ so we need $(1-\tau) \lambda+w_{0}=\lambda+w_{1}^{*}$.

Proposition 4. A $\operatorname{tax} \tau=\frac{w_{0}-w_{1}^{*}}{\lambda}$ on liquidation restores efficiency.

A couple of key ideas emerge here. The first is that the tax is mostly an out-of-equilibrium threat. Firms that are induced to continue do not in fact pay the tax. The tax is only paid by firms that liquidate. All infra-marginal firms with $z>\lambda+w_{0}$ are unaffected. Firms in the $\left[z^{*}, \hat{z}\right]$ range are affected but do not pay the tax in equilibrium. The tax is only paid by $F\left(z_{1}^{*}\right)-F_{0}\left(z_{0}^{*}\right)$ firms.

These appear to be very valuable features, and yet we do not see such taxes in reality. The main reason is probably that it would be a punishment for the owners of liquidated businesses. In the case of large firms the cost would be shared among diversified shareholders and creditors. In the case of small private firms, however, this would be a regressive tax on entrepreneurs who presumably lost much of the savings they had invested in their business in the first place.

A pure liquidation tax is therefore unlikely to be feasible, but the idea of discouraging liquidation, is, as we shall see, a robust insight.

\section{Efficient Debt Restructuring}

Let us now introduce a more realistic financial structure where firms have outstanding debts. At this point, it is important to separate macroeconomic and microeconomic inefficiencies.

In this section, I assume privately efficient restructuring, that is, I assume that renegotiations between the firm and its creditors are constrained efficient. This implies that creditors do not liquidate privately viable firms and it rules out, in particular, the classic debt overhang issue à la Myers (1977). Of course, a rich literature in corporate finance focuses on these precise issues, and I will discuss them in the next section. 


\subsection{Private debt restructuring $(D)$}

Firms carry legacy debt $D \geq \lambda$ and at least a fraction of that debt must be rolled over during COVID-19, so creditors have a say in the continuation of firms. I consider three cases:

1. If $z-w>D$, the firm is solvent;

2. If $D>z-w>\lambda$, the firm is insolvent but viable as a going concern;

3. If $\lambda>z-w$, the firm is not privately viable.

No further action is needed in case 1 . In case 2, the debt is restructured and the firm continues as a going concern. In case 3 , creditors always force liquidation. The marginal firm is therefore still defined by $\hat{z}=$ $\lambda+w$.

Proposition 5. The existence of private debt with efficient renegotiation does not change the post-COVID-19 equilibrium. With flexible wages we have the efficient equilibrium characterized by $z_{1}^{*}=\lambda+\gamma^{\prime}\left(1-F_{1}\left(z_{1}^{*}\right)\right)$. With downward rigid wages we have $\hat{z}_{1}=\lambda+w_{0}$ and excess unemployment $F_{1}\left(\lambda+w_{0}\right)-F_{1}\left(z_{1}^{*}\right)$.

For firms that are viable but insolvent the creditors agree to reduce their claims from $D$ to $D^{\prime}=z-w$. The haircut is therefore

$$
h=1-\frac{z-w}{D}
$$

for all $z \in[\lambda+w, D+w]$.

\subsection{Private debt and passive government loans, $(L)$}

As discussed in the introduction, governments implemented large-scale liquidity support during the lockdown. Some of this support took the form of direct wage subsidy, that is, grants to firms. The remainder took the form of loans, usually administered by commercial banks and guaranteed by governments (Baudino, 2020). In the simple model discussed here, a direct loan from the government and a loan guaranteed by the government are not conceptually different. We can thus think of $L$ as direct loans. These loans are usually pari passu with private debt.

Under liquidation and pari passu loans, private creditors recover $\frac{D}{D+L} \lambda$ while the government recovers $\frac{L}{D+L} \lambda$. Under continuation with a passive government policy that simply follows private restructuring agreements (if any), the private creditors can expect $\frac{D}{D+L}(z-w)$. The marginal firm is therefore still defined by $\hat{z}=w+\lambda$.

Lemma 4. Under passive government policy, the equilibrium is the same as under private debt.

As a corollary, this implies that the full information mitigation described earlier is unchanged.

\subsection{Optimal mitigation under limited information and rigid wages}

Here, I assume that private lenders observe $z$, but the government does not. With COVID-19 emergency loans ranging in the hundreds of thousands, it is clearly not feasible for governments to monitor all the borrowers. 
This implies that the government needs the help of banks to implement the efficient triage. However, letting the banks make privately optimal decisions would lead to excessive closures. Formally, I assume that the government does not observe firm-specific variables but can observe actions taken by private creditors.

Assumption. The information set of the government includes (a) whether or not a private restructuring agreement has been reached; (b) the haircut agreed on private debt; and (c) the state of the labor market.

We can now state our main result.

Theorem 1. Continuation premium. The following policy implements the efficient allocation. Under liquidation, the government claims all its rights as a creditor. Under continuation, the government automatically agrees to a haircut $(H)$ equals to the one granted by private creditors $(h)$ plus a continuation premium: $H(z)=h(z)+\theta^{*}$, with

$$
\theta^{*} \equiv \frac{w_{0}-w_{1}^{*}}{L}
$$

Proof. Let $D^{\prime}$ and $L^{\prime}$ be the new claims under continuation. If private creditors liquidate they recover $\frac{D}{D+L} \lambda$. If they restructure and continue they get $D^{\prime}<D$. They are indifferent if and only if $D^{\prime}=\frac{D}{D+L} \lambda$ or $1-h=\frac{\lambda}{D+L}$. The pledgeability constraint imposes $D^{\prime}+L^{\prime}=z-w$. Combining these two condition we get $L^{\prime}=z-w-\frac{D}{D+L} \lambda$. We evaluate at the efficient allocation $z^{*}=\lambda+\gamma^{\prime}\left(N^{*}\right)$ to get

$$
\begin{aligned}
& L^{\prime}=\lambda+\gamma^{\prime}\left(N^{*}\right)-w-\frac{D}{D+L} \lambda \\
& \frac{L^{\prime}}{L}=\frac{\lambda}{D+L}+\frac{\gamma^{\prime}\left(N^{*}\right)-w}{L}
\end{aligned}
$$

or

$$
H=h+\frac{w-\gamma^{\prime}\left(N^{*}\right)}{L}
$$

This shows that private creditors are indifferent between liquidating and continuing for a firm of quality $z^{*}$. Any firm $z>z^{*}$ strictly prefers to continue, since they only need to set a haircut $h$ such that

$$
\begin{aligned}
(1-h)(D+L) & =z-w+\theta L \\
& =z-\gamma^{\prime}\left(N^{*}\right) \\
& =z-z^{*}+\lambda,
\end{aligned}
$$

which shows that $(1-h(z))(D+L)>\lambda$ for all $z>z^{*}$. QED.

The key point is that the continuation premium $\theta \equiv \frac{w_{0}-\gamma^{\prime}\left(N^{*}\right)}{L}$ does not depend on the individual value of $z$ or on $\lambda$. The scheme is therefore implementable by a government with limited microeconomic information. The term $w_{0}-\gamma^{\prime}\left(N^{*}\right)$ captures excessive unemployment. It measures the gap between the wage and the shadow cost of labor. If wages were fully flexible and the labor market fully efficient and competitive, we would have $w=\gamma^{\prime}(N)$ and the gap would be zero. 
Implementing the optimal allocation is costly. Because the government does not observe $z$, it needs to pay information rents to creditors. These rents are zero only for the marginal firms $\left(z^{*}\right)$. They are strictly positive for all insolvent firms above $z^{*}$. This means that mitigation under limited information is costlier than full information mitigation.

Corollary 1. Limited information mitigation is costlier than full information mitigation.

If taxes are distortionary it may not optimal to implement the first best allocation. In that case, the government can rely on a limited mitigation. The key point here is that it is still optimal to use a continuation premium because it leverages private sector information.

Corollary 2. When taxes are distortionary, mitigation below the first best can be obtained by a continuation premium $\theta<\theta^{*}$.

This last case also applies if the government is unsure about the value of $w_{1}^{*}$ or has a different goal for employment, say $N_{g}$ instead of $N_{1}^{*}$. Suppose the government sets a continuation premium $\theta$. If private creditors liquidate they recover $\frac{D}{D+L} \lambda$. If they restructure and continue they get $D^{\prime}<D$. They are indifferent if and only if $D^{\prime}=\frac{D}{D+L} \lambda$ or $1-h=\frac{\lambda}{D+L}$. The pledgeability constraint imposes $D^{\prime}+L^{\prime}=z-w$. Combining these two condition we get $(1-h) D+(1-h-\theta) L=z-w$ or

$$
z(\theta)=w+\lambda-\theta L
$$

Corollary 3. The continuation premium $\theta^{g}$ implements the employment level $N_{1}^{g}=1-F_{1}\left(z_{1}^{g}\right)$ where $z_{1}^{g}$ solves (7).

Note that the government needs an estimate of the average value of $\lambda$ to predict the aggregate level of employment it will generate. It does not need to know the value of $\lambda$ at the micro level, however.

\section{Pledgeability Constraints and Private Inefficiencies}

In the previous section, we assumed that debt restructuring is privately efficient. This assumption is clearly not true in the real world. We can think of two private inefficiencies. The first is simply a deadweight loss in bankruptcy. It is not clear, however, that this creates the need for specific interventions. In fact, neither the labor subsidy $s=\frac{w_{0}-w^{*}}{w_{0}}$ nor the continuation premium $\theta \equiv \frac{w_{0}-\gamma^{\prime}\left(N^{*}\right)}{L}$ depend on $\lambda$. Private agents take $\lambda$ into account when deciding to liquidate or restructure a business. A lower value of $\lambda$ makes liquidation more costly, but this is internalized by private agents. The externality only arises if bankruptcy by one firm lowers the recovery values of other firms, for instance, because bankruptcy courts are overwhelmed with cases. Even in this case, however, the direction of the bias is unclear, since we have seen that a tax on liquidation is typically useful.

A more interesting private inefficiency is that of credit constraints, broadly defined to encompass debt overhang and pledgeability constraints. Debt overhang is a consequence of inefficient private bargaining as senior creditors refuse to renegotiate their debt $D$. Philippon and Schnabl (2013) have explored the consequences of debt overhang so we refer the reader to that paper for more details. 
My model can easily accommodate credit constraints. The key feature in this case is a lack of transferability of utility. Formally, suppose that total firm value is $z-w$ but insiders must retain inside equity $e$, so pledgeable income is only $z-w-e$. As is well-known in corporate finance theory, pledgeability constraints can arise because of moral hazard or adverse selection, and can take the form of leverage constraints, credit risk constraints, or inside equity constraints (Tirole, 2006). The results below do not depend on the exact nature of the constraint. The important point is the existence of a gap between the total private value of the firm and its pledgeable value. The value $e$ accrues to the entrepreneur, but creditors do not care about it, and the entrepreneur cannot pledge it to keep her business open.

\subsection{Private and social continuation values}

The three cases are now

1. If $D<z-w-e$, the firm is solvent;

2. If $\lambda<z-w-e<D$, the firm is insolvent but privately viable as a going concern;

3. If $z-w-e<\lambda<z-w$, the firm is socially viable, but not privately viable.

4. If $z-w<\lambda$, the firm is not socially viable.

The marginal firm is then defined by

$$
\hat{z}=w+e+\lambda
$$

Proposition 6. Pledgeability constraints increase liquidation and unemployment. With flexible wages the equilibrium is characterized by $\hat{z}=\lambda+e+\gamma^{\prime}(1-F(\hat{z}))$ and $\hat{z}>z^{*}$. With downward rigid wages, we have $\hat{z}=\lambda+w_{0}+e$ and excess unemployment $F(\hat{z})-F\left(p^{*}\right)$.

For firms that are viable but insolvent, creditors agree to reduce their claims from $D$ down to $D^{\prime}=$ $z-w-e$. The haircut is therefore

$$
h(z)=1-\frac{z-w-e}{D}
$$

for all $z \in[\lambda+w+e, D+w+e]$. We can introduce debt owed to the government as we did earlier. The equilibrium under passive government policy is the same as under private debt.

The full information mitigation is also similar, but the efficient subsidy takes into account the welfare of the business owner.

Lemma 5. The mitigation policy where the government offers $m(z)=\lambda+w+e-z$ for all $z \in\left(z^{*}, \hat{z}\right)$ and $m=0$ otherwise implements the efficient allocation $\left(z^{*}, N^{*}\right)$.

\subsection{Optimal mitigation}

Mitigation under imperfect information works in a similar way as before. 
Theorem 2. Continuation premium with pledgeability constraint. The following policy implements the efficient allocation. Under liquidation, the government claims all its rights as a creditor. Under continuation, the government automatically agrees to a haircut $(H)$ equals to the one granted by private creditors $(h)$ plus a continuation premium: $H=h+\theta^{*}$, with

$$
\theta^{*}=\frac{w_{0}-\gamma^{\prime}\left(N^{*}\right)+e}{L}
$$

The continuation premium now includes a second component that captures the nonpledgeable equity of business owners that would be destroyed under liquidation.

\subsection{Robustness}

An important point is that the scheme in Theorem 2 is robust to manipulation of valuations by creditors because the government's efforts are conditional on the haircut of private creditors.

In theory, the scheme can be vulnerable to collusion between creditors and entrepreneurs. Creditors could propose a high haircut in order to induce a high haircut from the government. This would benefit the firm, not the creditors, but if private side payments are feasible, the entrepreneur could secretly share the windfall with the creditors. However, how such a payment could be enforced is unclear, so the creditors would be taking a risk. They would also have to recognize large losses. It seems unlikely that banks would engage in such a scheme.

\section{Conclusion}

The results derived above shed light on the various approaches used by governments to limit the economic cost of the pandemic. Governments have reacted to the risk of excessive liquidation and unemployment by launching guarantee programs to support SMEs (Prop 1). Various forms of wage subsidies have been enacted everywhere, but their costs have led many governments to restrict their availability to a subset of firms and industries (Prop. 3).

Even as the pandemic recedes, firms will be left with large amounts of debt and the question of how to allocate the restructuring costs will become crucial. An important difference with previous recessions is that governments will be major creditors to millions of SMEs. In this context, Theorems 1 and 2 establish a scheme that supports efficient continuation and restructuring while minimizing the cost to taxpayers.

An important avenue for future research is to understand the political economy of loss sharing. The scheme proposed in this paper is robust to manipulations at the micro level. At the macro level, however, groups of creditors might lobby governments to convince them to unconditionally abandon their claims, which would be both inefficient and costly. 


\section{References}

Alvarez, F., D. Argente, and F. Lippi (2020, March). A simple planning problem for covid-19 lockdown. Working Paper.

Baudino, P. (2020, April). Public guarantees for bank lending in response to the covid-19 pandemic. FSI Briefs.

Blanchard, O., T. Philippon, and J. Pisani-Ferry (2020). A new policy toolkit is needed as countries exit covid-19 lockdowns. PIEE.

Brunnermeier, M. and A. Krishnamurthy (2020, June). Corporate debt overhang and credit policy. Brookings.

Carletti, E., T. Oliviero, M. Pagano, L. Pelizzon, and M. G. Subrahmanyam (2020, 08). The covid-19 shock and equity shortfall: Firm-level evidence from italy. The Review of Corporate Finance Studies 9(3), $534-568$.

Eichenbaum, M., S. Rebelo, and M. Trabandt (2020, March). The macroeconomics of epidemics. Working Paper NWU.

Glode, V. and C. Opp (2020). Renegotiation in debt chains. NBER WP 27883.

Gourinchas, P.-O., Ș. Kalemli-Özcan, V. Penciakova, and N. Sander (2020). Covid-19 and sme failures. NBER WP 27877.

Guerrieri, V., G. Lorenzoni, L. Straub, and I. Werning (2020, April). Macroeconomic implications of covid19: Can negative supply shocks cause demand shortages? NBER Working Paper No. 26918.

Hanson, S., J. Stein, A. Sunderam, and E. Zwick (2020). Business credit programs in the pandemic era. Brookings.

Jones, C., T. Philippon, and V. Venkateswaran (2020, April). Optimal mitigation policies in a pandemic: Social distancing and working from home. NBER Working Paper 26984.

Myers, S. C. (1977). Determinants of corporate borrowing. Journal of Financial Economics 5, 147-175.

Philippon, T. and P. Schnabl (2013, February). Efficient recapitalization. Journal of Finance 68(1), 1-42.

Philippon, T. and V. Skreta (2012, February). Optimal interventions in markets with adverse selection. American Economic Review.

Schivardi, F., E. Sette, and G. Tabellini (2020, 07). Identifying the real effects of zombie lending. The Review of Corporate Finance Studies 9(3), 569-592.

Tirole, J. (2006). The Theory of Corporate Finance. Princeton University Press. 